\title{
MULTIMODALIDADE E HIPERTEXTUALIDADE: CAMINHOS PARA PESQUISA E ENSINO
}

\section{MULTIMODALITY AND HYPERTEXTUALITY: PATHS FOR RESEARCH AND TEACHING}

\author{
Clarice Gualberto ${ }^{1}$ \\ Záira Santos ${ }^{2}$
}

\begin{abstract}
RESUMO: Neste trabalho, com base no entendimento de que todo texto é multimodal e também um hipertexto, tecemos algumas reflexões em torno das contribuições da Semiótica Social Multimodal (KRESS, 2010, 2011, 2015) e da Linguística Textual (KOCH, 2005; XAVIER, 2002) para se pensar texto e a hipertextualidade. Para tanto, abordamos (a) as dimensões conceituais entre texto, hipertexto e multimodalidade; (b) percursos metodológicos que podem ser trilhados para o desenvolvimento de pesquisa e (c) aspectos que precisam ser observados e considerados em análises multimodais. A partir dessa discussão, buscamos demarcar como essas noções se imbricam e são interdependentes no processo de produção e recepção dos textos.
\end{abstract}

PALAVRAS-CHAVE: Multimodalidade. Hipertextualidade. Pesquisa. Ensino.

ABSTRACT: Based on the understanding that every text is multimodal and a hypertext, we reflect on contributions of Multimodal Social Semiotics (KRESS, 2010, 2011, 2015) and Textual Linguistics (KOCH, 2005; XAVIER, 2002) to discuss text and hypertextuality. To do so, we focus on (a) conceptual dimensions of text, hypertext and multimodality; (b) methodological paths that can be adopted for the development of research and (c) aspects that need to be observed and considered in multimodal analysis. By doing this, we aim to demarcate how these notions are intertwined and interdependent in the process of production and reception of texts.

KEYWORDS: Multimodality. Hipertextuality. Research. Teaching.

\footnotetext{
${ }^{1}$ Pós-doutorado em Semiótica pelo programa de Pós-Graduação em Estudos Linguísticos da Universidade Federal de Minas Gerais (PosLin - UFMG). Integrante do grupo GEMULTE/UFES/CEUNES - (Multi)letramentos, Leitura e Textos. E-mail: clagualberto@gmail.com.

${ }^{2}$ Professora adjunta da Universidade Federal do Espírito Santo - CEUNES/UFES no Departamento de Educação e Ciências Humanas - DECH e professora Permanente no Programa de Pós-graduação em Ensino na Educação Básica - PPGEEB CEUNES/UFES. Líder do grupo GEMULTE/UFES/CEUNES - (Multi)letramentos, Leitura e Textos e integrante do grupo de Pesquisa SAL - Sistêmica, Ambientes e Linguagens. E-mail: zbomfante@gmail.com.
} 


\section{PERcursos Linguísticos • Vitória (ES) •v. 11 •n. 29 • 2021 • ISSN: 2236-2592 • Dossiê temático $\bullet O$ texto na pesquisa e no ensino: conhecimentos, práticas e desafios na contemporaneidade •}

\section{Considerações iniciais}

[...] Todos os textos são multimodais (Kress e van Leeuwen, 1998, p.186)

[...] Todo texto é um hipertexto. (Koch, 2005, p. 61)

As epígrafes apontam para uma característica inerente a todo texto, justamente por ele carregar em si diversas camadas modais (palavra, imagem, diagramação, som, hiperlinks, design de cores e tipografias etc). O texto é tecido por diversos fios semióticos, que ocorrem de forma múltipla e plurilinear. Assim, todo texto não é de um único sentido, mas uma proposta de sentidos múltiplos. Adicionalmente, graças aos avanços tecnológicos, a partir da web 2.0, vemos imbricações nos textos verbais (escrito e oral) e visuais (imagem estática e em movimento), que mudaram a paisagem comunicacional e as formas de produção escrita e de leitura.

Essa perspectiva vai ao encontro da visão bakhtiniana quando situa que viver significa participar de um diálogo por meio do qual o homem se insere com toda a sua vida: com olhos, com os lábios, as mãos, a alma, o espírito, o corpo e todos os seus efeitos, investindo o seu ser no discurso, o qual penetra no tecido dialógico da vida humana. Logo, o mundo pronunciado pelos homens revela a sua existência; assim, o seu lugar ganha materialidade e concretude no que definimos por texto $(s)$.

O termo texto guarda uma diversidade de concepções muito próximas a modelos teóricos e pesquisas, os quais contribuíram para a formação do seu conceito, o que não deixa de ser algo natural, demonstrando evidências da renovação teórica num processo ininterrupto de criação nos estudos linguísticos. A noção de texto vem assumindo proeminência como um conceito muito abrangente para todos os tipos de trabalho como romances, livros, pinturas, anúncios, mídia eletrônica, filmes, obras e espetáculos teatrais (COLLOW, 2005). Os benefícios dessa abordagem mais textual, segundo Kress (2002), são muitos; mas, ao mesmo tempo, qualquer abordagem de um determinado campo privilegiará, por necessidade, uma visão em detrimento de outras possibilidades.

Adicionalmente, é muito comum nos deparamos com a noção de hipertexto, um termo que tem sido intensamente discutido, pesquisado e utilizado. Essa noção nos provoca a pensar nas camadas do texto, no armazenamento, na concatenação e na associação de informações. Menezes e Nascimento (2009) situam historicamente o percurso do conceito e asseveram que 


\section{PERcursos Linguísticos • Vitória (ES) •v. 11 •n. 29 • 2021 • ISSN: 2236-2592 • Dossiê temático $\bullet O$ texto na pesquisa e no ensino: conhecimentos, práticas e desafios na contemporaneidade •}

sua gênese é atribuída a Vannevar Bush desde 1945, a partir de suas preocupações com formas de armazenamento de informações, disponíveis na sua época. Vinte anos depois, em 1965, o termo é cunhado por Ted Nelson, ao se inspirar num artigo de Wedeless, afirmando que "não pensamos em sequências lineares, mas em espirais e em notas de rodapé". Logo, o conceito de hipertexto foi introduzido como uma forma "mais flexível, mais generalizada, e não-linear de apresentação de material sobre um assunto específico" (p. 521)

Nesses moldes, muito se tem debatido em torno dessa noção e os seus desdobramentos para o processo de produção escrita, leitura, autoria entre outros. No Brasil, diversos pesquisadores têm desenvolvido investigações sobre texto, hipertexto, multimodalidade e direcionado muitas pesquisas para o ensino. $\mathrm{O}$ trabalho com o hipertexto tem despertado o interesse de estudiosos como Coscarelli (2002), Xavier (2002), Koch (2005), Paiva e Nascimento (2006, 2009), Marcuschi (2005), Ribeiro (2008) bem como trabalhos sobre multimodalidade como Pimenta (2006), Heberle e Abreu (2011), Santos (2013), Gualberto (2016), Barbosa (2017), Gualberto e Santos (2019) etc. Além da Rede Latino Americana de Estudos em Multimodalidade (REDLEM), que busca promover e integrar investigações sobre multimodalidade na América Latina e Caribe. A partir dessa perspectiva, nosso objetivo neste trabalho consiste em discutir as noções de texto, hipertexto, multimodalidade e os seus desdobramentos na paisagem comunicacional, aventando alguns caminhos para pensar o desenvolvimento de pesquisas em torno do ensino.

É comum termos como multimodalidade, hipertexto, design, modo visual, modo verbal, recursos etc. irem se acomodando em nosso vocabulário, sem necessariamente estarmos situados numa esfera comunicativa na área de linguagem, comunicação, educação ou numa comunidade de pesquisa que envolvam essas áreas. Agasalhamos esses termos e, frequentemente, não temos a dimensão da interdependência ou imbricação que eles possuem. Com base em tais ponderações, o presente trabalho propõe uma reflexão sobre a contribuição dos estudos da Semiótica Social Multimodal para se pensar a (hiper)textualidade. Além destas considerações iniciais, o trabalho é constituído de três partes principais, cujos objetivos são: $(i)$ apresentar uma discussão conceitual das premissas que norteiam a Semiótica Social multimodal situando dimensões conceituais; (ii) articular essas premissas a percursos metodológicos que podem ser trilhados para o desenvolvimento de pesquisas e por último; (iii) enfatizar aspectos relevantes para se pensar análises multimodais. 


\section{PERcursos Linguísticos • Vitória (ES) •v. 11 •n. 29 • 2021 • ISSN: 2236-2592 • Dossiê temático $\bullet O$ texto na pesquisa e no ensino: conhecimentos, práticas e desafios na contemporaneidade •}

\section{Semiótica Social Multimodal - Uma outra Semiótica?}

A Semiótica Social Multimodal inaugura uma fase de estudos pós-estruturalistas, cujo foco recai no processo de significação e sua recepção, situando-os como parte da construção social. Segundo resumem Kress e van Leeuwen (2006), a Semiótica Social é a terceira escola semiótica que sucederam a primeira escola, denominada escola de Praga a partir da linguística estudada pelos Formalistas Russos; a segunda escola, denominada escola de Paris, marcada pela extensão das ideias de Saussure para os estudos em moda e fotografia (Barthes), cinema (Metz), música (Nattiez), entre outros. A Semiótica Social marca o início dos estudos aplicados a textos ao considerar todos os modos semióticos orquestrados em sua constituição.

Em 1988, Hodge e Kress lançam livro Social Semiotics, marcando uma nova fase para os estudos semióticos, muito influenciado pelas contribuições de Michael Alexander Kirkwood Halliday. Halliday (1978) traz, para os estudos da linguagem, a expressão Semiótica Social em sua obra Language as social semiotic: the social interpretation of language and meaning. Dez anos mais tarde, ao lançar a obra Social Semiotics, Hodge e Kress (1988) ressaltam que

\footnotetext{
Muitas pessoas contribuíram com ideias, críticas e materiais em vários estágios da lenta gestação deste livro, cuja ajuda agradecemos. De muitos escritores que nos influenciaram e que são mencionados em referências, gostaríamos de destacar M. A. K. Halliday, não apenas por seus textos teóricos, como Linguagem como Semiótica Social, mas por seus exemplos inspiradores como pesquisador, professor e explorador das funções sociais da linguagem (p. 9).
}

Ao demarcar a influência do pensamento hallidayano em seus trabalhos, Hodge e Kress trazem, para o centro da discussão, os desdobramentos da Linguística SistêmicoFuncional, cujo foco está centrado (i) nas funções sociais da linguagem, (ii) na noção de escolha do sistema de linguagem e (iii) as configurações de significado a partir do contexto. Hodge e Kress (1988) ampliam a compreensão de Halliday (1978) ao centrar nas práticas sociais de criação de significados de todos os tipos, sejam eles visuais, verbais ou aurais, ratificando as ideias hallidayanas de que existem muitos outros modos de significação em qualquer cultura que estão fora do reino da língua.

Adicionalmente, em relação à abordagem Semiótica Social Multimodal, Kress (2011) situa que 


\title{
PERcursos Linguísticos • Vitória (ES) •v. 11 •n. 29 • 2021 • ISSN: 2236-2592 • Dossiê temático $\bullet O$ texto na pesquisa e no ensino: conhecimentos, práticas e desafios na contemporaneidade •
}

\begin{abstract}
Uma abordagem Semiótica Social Multimodal fornece uma perspectiva mais rica sobre os muitos meios envolvidos na construção de significado e aprendizagem; em formas e formatos de conhecimento; nas muitas formas de avaliação; nas relações sociais [...]; na (auto-)construção da identidade; nos meios que são centrais no reconhecimento da agência e dos muitos tipos de trabalho semiótico (KRESS, 2011, p. $\left.208^{3}\right)$
\end{abstract}

Para o autor, a Semiótica multimodal comporta alguns aspectos:

$\checkmark$ Semiótica Social - Fornece um quadro teórico para enfocar todos os aspectos de construção de sentido: sobre os agentes que fazem signos complexos como textos; nos processos de construção de significado e nas entidades teóricas que estão envolvidas nisso - signo, texto, gênero, discurso, interesse, como exemplos;

$\checkmark$ Multimodalidade - centra-se nos meios materiais de representação, nos recursos para fazer textos: isto é, nos modos.

Essas duas características estão inteiramente interconectadas em todos os momentos, contudo, possuem suas respectivas distinções. Na visão de Kress (2011), as consequências educacionais de uma abordagem semiótica social multimodal derivam de ambos os aspectos e com os seus distintos focos. O termo multimodalidade ressalta a diversidade de recursos materiais além da fala e da escrita que as sociedades moldaram e que as culturas fornecem como meios para produção de significados. Nas palavras de van Leeuwen (2017), multimodalidade é “[...] o estudo de como significados podem ser construídos, e de fato são construídos em contextos específicos, com diferentes meios de expressão ou 'modos semióticos'” (p. $5^{4}$ ). Assim, ela foca nas características distintas dos diferentes modos. Não é uma teoria, embora sua compreensão traga um desafio para o lugar da linguagem e profundas implicações para pensar os significados, a representação e comunicação.

A Semiótica Social é uma teoria sobre a construção de significados em processos de interação na comunicação. Na visão de Kress (2011), é uma teoria sobre a criação de signos em todos os modos disponíveis em uma cultura. Logo, o signo é visto como um trabalho semiótico

\footnotetext{
${ }^{3}$ No original: "A multimodal social semiotic approach provides a richer perspective on the many means involved in making meaning and learning; on forms and shapes of knowledge; on the many forms of evaluation and assessment; on the social relations evident in pedagogy; on the (self-)making of identity and, in that, on the means that are central in the recognition of the agency and of the many kinds of semiotic work of learners in learning." (KRESS, 2011, p. 208).

${ }^{4}$ No original: "Multimodality is therefore the study of how meanings can be made, and actually are made in specific contexts, with different means of expression or 'semiotic modes' [...]" (VAN LEEUWEN, 2017, p. 5).
} 


\section{PERcursos Linguísticos • Vitória (ES) •v. 11 •n. 29 • 2021 • ISSN: 2236-2592 • Dossiê temático $\bullet O$ texto na pesquisa e no ensino: conhecimentos, práticas e desafios na contemporaneidade •}

dos agentes sociais. Portanto, a Semiótica Social lida com a avaliação do produtor do signo em relação ao ambiente de comunicação. Noutras palavras, lida com a avaliação retórica dos participantes, ocasião, objetos envolvidos ligados a práticas moldadas por relações de poder. A teoria inclui atenção aos meios de disseminação/circulação, ou seja, as mídias envolvidas. A ênfase recai, portanto, na produção de signo ao invés do uso do signo, visto que, para a perspectiva socialmente orientada, os signos são produzidos a cada interação e não usados. O ponto central da teoria está na visão de signo motivado, ou sejam a junção de forma e significado, que é produto da agência e do interesse do produtor. Esses aspectos ressaltam as perspectivas que norteiam a Semiótica Social Multimodal para o processo de produção de signos e, consequentemente, as implicações para se pensar o (hiper) texto, a sua produção e recepção.

\section{Multimodalidade, Texto e Hipertexto: Coisas distintas ou tudo a mesma coisa?}

A pergunta que intitula esta seção faz uma provocação para delimitarmos nossas lentes e dimensionar o olhar para os textos que se deflagram nas diversas práticas sociais de linguagem. Não estamos problematizando conceitos no intuito de criar dicotomias, mas buscamos compreender as interrelações que são estabelecidas e como podemos potencializar essas relações. Sabemos que vivemos em uma sociedade textualizada, leitura e escrita estão em toda parte e dialogamos com inúmeras interfaces semióticas. Nesse sentido, Cope e Kalantzis (2006) situam que "toda construção de significado é considerada multimodal, não podendo existir em uma única modalidade, mas tendo uma dela sempre predominante" (p. 9).

A partir dessas considerações, vemos que o termo multimodalidade ou multimodal parece ser recorrente para designar algo muito comum e característico da comunicação. Segundo Kress e van Leeuwen (2001), o termo virou até um modismo, estando em toda parte. Ele aparece na década de 90 em diferentes países com abordagens distintas, sendo impulsionado com publicações como a de Charles Goodwin (1998) sobre etnometodologia e análise da conversação para Journal of Pragmatics, em 1996, com as contribuições de Kress e van Leeuwen na obra Reading Images: The grammar of visual Design e em 2001 com a obra Multimodal Discourse.

Dada a recorrência do termo, Kress (2015) afirma que ele é oscilante ou ambíguo e até mesmo uma noção vaga para se referir ao que está externo, fora do mundo sociossemiótico. $\mathrm{Na}$ visão do autor, o uso do termo na área de Ciências Humanas e Sociais abrange um amplo espectro do que pode caracterizar "posições de senso comum" e "posições baseados na teoria" 


\section{PERcursos Linguísticos • Vitória (ES) •v. 11 •n. 29 • 2021 • ISSN: 2236-2592 • Dossiê temático $\bullet O$ texto na pesquisa e no ensino: conhecimentos, práticas e desafios na contemporaneidade •}

(p. 53). Ao usar a expressão "posições de senso comum", o autor cita trabalhos em que pesquisadores fazem ajustes para dar conta de alguns aspectos, deixando em proeminência as perspectivas teóricas existentes e suposições em vigor. Já "posições baseadas na teoria" integram a multimodalidade no quadro teórico que utilizam. Kress (2015) deixa claro seu posicionamento "baseado em teoria" para falar e pesquisar sobre agência, criação de significados, interesse, signos dentre outros. Logo, a teoria em que se baseia é a Semiótica Social, a qual trata da "criação de significado como criação de signos com todos os modos que estão disponíveis em uma cultura, onde a criação de signos é vista como o trabalho semiótico dos agentes sociais" (KRESS, 2011, p. 2095).

Ao delimitar um conjunto de reflexões epistemológicas e metodológicas no quadro da Semiótica Social, deparamo-nos com sua preocupação em discutir o processo de produção de signo (sign-making), significado (meaning making) e sua recepção, situando-os como parte da construção social. A Fig. 1, a seguir, mostra alguns aspectos importantes dentro da Semiótica Social.

Figura 1: Aspectos relacionados ao sentido no escopo da Semiótica Social

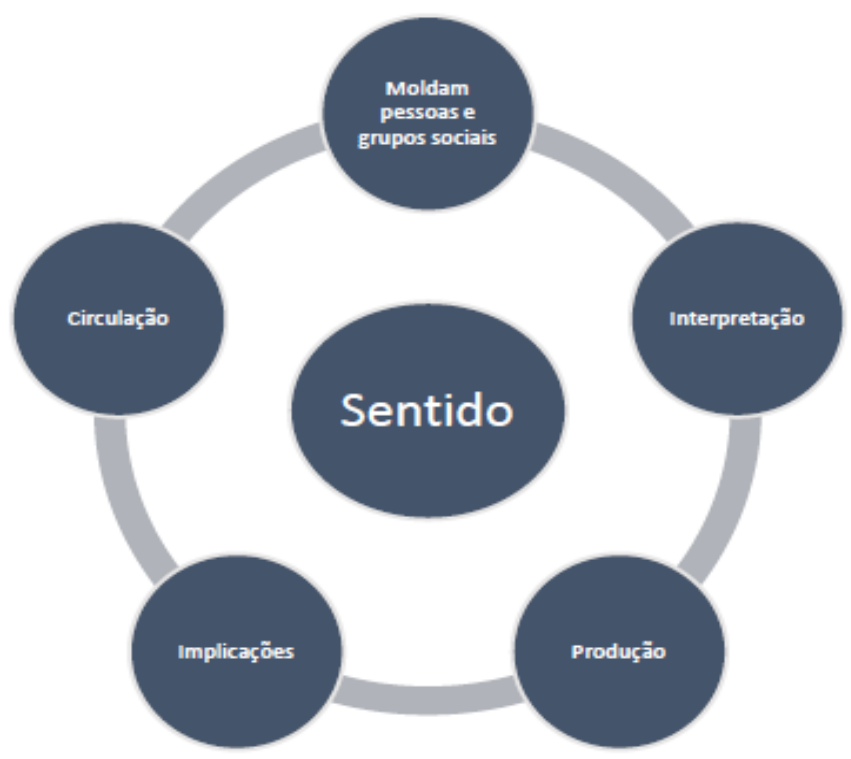

Fonte: elaboração das autoras

\footnotetext{
${ }^{5}$ No original: "it is a theory about meaning-making as sign-making with all the modes that are available in a culture, where sign-making is seen as the semiotic work of social agents." (KRESS, 2011, p. 209).
} 


\section{PERcursos Linguísticos • Vitória (ES) •v. 11 •n. 29 • 2021 • ISSN: 2236-2592 • Dossiê temático $\bullet O$ texto na pesquisa e no ensino: conhecimentos, práticas e desafios na contemporaneidade •}

Nessa perspectiva, observamos que usar o termo multimodalidade não se resume a adicionar outros modos dentro de uma mistura, é muito mais do que colocar a atenção em outros modos de produzir significados, pois as escolhas de um modo em detrimento de outro trazem implicações do que é e pode ser comunicado e aprendido. É elementar, no processo de produção de sentido, levar em consideração a circulação, a interpretação, as implicações dentro desse processo e como os significados moldam as pessoas e os grupos sociais.

Logo, é importante destacar conceitos-chaves que são delimitados no escopo da teoria que nos auxiliam olhar para o texto e sua composição multimodal, bem como refletir sobre processo de produção, circulação e interpretação de sentidos no contexto cultural. Ressaltamos que o intuito deste trabalho não consiste em compilar ou desenvolver tais conceitos problematizados no interior da teoria, dada a sua complexidade. Contudo, buscamos trazê-los para demarcar como direcionam para uma concepção de língua, sujeito, modos e recursos no processo de produção de sentido, mostrando a interdependência entre eles.

Figura 2: Conceitos-chave da Semiótica Social

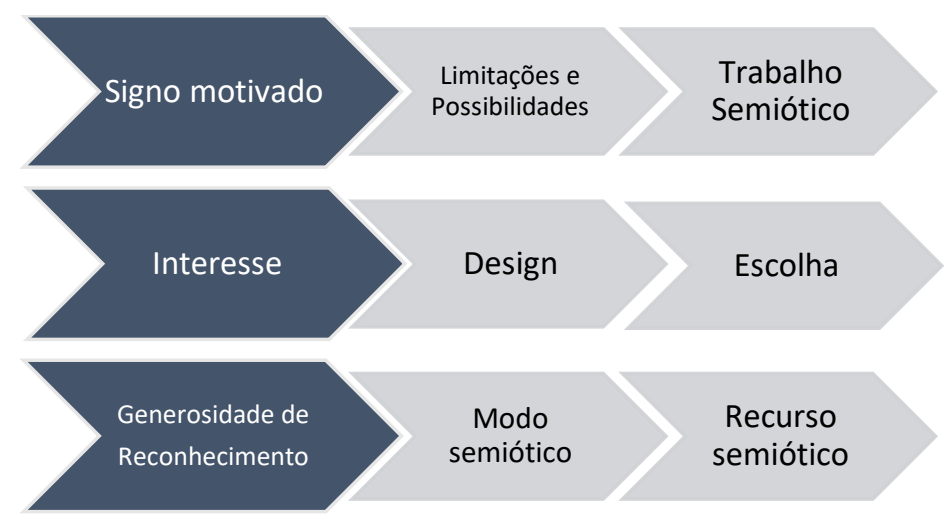

Fonte: elaboração das autoras

Dentre os conceitos elencados da Figura 2, Kress (1997) ao tratar do caráter não arbitrário do signo dentro do escopo da Semiótica Social Multimodal, enfatiza a noção de interesse e escolha de quem produz um signo por meio de uma relação motivada entre significante e significado, e, portanto, signos motivados”. Esse caráter motivado do signo demonstra sua gênese social, já que "o interesse dos produtores da representação/signo os leva a escolher um aspecto daquilo que querem representar, sendo este o critério naquele momento 


\section{PERcursos Linguísticos • Vitória (ES) •v. 11 •n. 29 • 2021 • ISSN: 2236-2592 • Dossiê temático $\bullet O$ texto na pesquisa e no ensino: conhecimentos, práticas e desafios na contemporaneidade •}

para a representação de um objeto; eles, então, escolhem a forma mais plausível que está disponível para sua representação" (KRESS, 1997, p. 14) ${ }^{6}$.

Em relação à generosidade de reconhecimento, ela está ligada aos aspectos que devemos reconhecer e aos quais devemos dar atenção no processo de produção de signo. Na percepção de Bezemer e Kress (2016), comunicação e aprendizagem estão intrinsicamente ligadas, constituem-se mutuamente e estão num domínio integrado de construção de significado. Assim, se os signos de aprendizagem não forem reconhecidos, eles não podem ser nem avaliados e nem, portanto, valorizados. Na visão dos autores, todos os signos "precisam ser levados a sério, independente de quem o produziu ou que modo foi utilizado" (p.5). Contudo, é necessária uma avaliação do ambiente em que o signo foi produzido ao invés de rotular a produção como "erro" ou produtor do signo como "incompetente". É importante investigar e estabelecer princípios semióticos aplicados pelos produtores do signo.

A rigor, todos esses conceitos vão delineando uma visão de texto dentro do escopo da teoria. Dentro do quadro teórico da Semiótica Social Multimodal, o texto é compreendido como objetos materiais, os quais são

\footnotetext{
[...] em parte, constitutivos das instituições sociais; proporcionam meios de "leitura" dos interesses e propósitos dos envolvidos na produção de textos em uma instituição; eles revelam os significados e os processos envolvidos em sua feitura. Os textos são resultados de processos iniciados e realizados por agentes sociais por razões sociais; e fornecem um meio de obter informações sobre esses processos e as finalidades dos agentes sociais (KRESS, 2011, p. $205^{7}$ )
}

As noções demarcadas colocam o texto como um artefato que se produz dentro de uma cultura, a partir dos modos e recursos que ela disponibiliza e do trabalho semiótico dos agentes sociais numa interação social que se materializa num conjunto multimodal. Nessa via, todos os significados que produzimos são complexos; essa projeção complexa de diferentes modos é vista como texto.

Ainda nessa direção conceitual, vários outros pesquisadores trazem uma visão que busca em grande medida, dialogar, complementar, ressaltar outros aspectos em relação à visão de texto. Ancorando-se nos estudos da Linguística Textual, Koch e Elias (2009) situam o texto como uma entidade multifacetada, fruto de um processo extremamente complexo de interação

\footnotetext{
${ }^{6}$ Tradução de: "The interest of makers of the representation/sign leads them to choose one aspect of the thing they want to represent as being criterial at that moment for the representation of an object; they then choose the most plausible form which is available to them for its representation." (KRESS, 1997, p. 14)

${ }^{7}$ No original: "Texts - as material objects - are in part constitutive of social institutions; they provide means of 'reading' the interests and purposes of those involved in the making of texts in an institution; they reveal the meanings and the processes involved in their making". (KRESS, 2011, p. 205).
} 


\title{
PERcursos Linguísticos • Vitória (ES) •v. 11 •n. 29 • 2021 • ISSN: 2236-2592 • Dossiê temático $\bullet O$ texto na pesquisa e no ensino: conhecimentos, práticas e desafios na contemporaneidade •
}

social de conhecimento da linguagem. A partir das contribuições e reflexões dos estudos da Semiótica Social e da Linguística Textual, Gualberto, Santos e Meira (2020) sintetizam a visão de texto:

\begin{abstract}
[...] a nossa compreensão de texto vai se constituindo, por meio do diálogo com as vozes de Beaugrande (1997), Cope e Kalantzis (2006) e Kress e van Leeuwen (2001), ao vislumbrá-lo como um evento comunicativo em que convergem ações linguísticas, culturais, sociais e cognitivas que vai se tecendo por uma malha de fios semióticos motivados, possibilitando novos designs, formas de interação e representação em um contexto comunicativo. Em outros termos, os sentidos vão se construindo em formas cada vez mais multimodais - nas quais modos representacionais interagem com padrões espaciais, táteis, gestuais, auditivos e orais de significação (p. 896)
\end{abstract}

Considerando a diversidade de conceitos sobre texto que vão se entrelaçando, podemos problematizar alguns questionamentos, baseados em Kress (2011 e 2015), para pensar a produção de sentido global do texto, tais como:

$\checkmark$ Como compreender o papel e a parcialidade de cada modo no trabalho semiótico?

$\checkmark$ Em nível macro, é possível olhar para o todo e ver as partes?

$\checkmark$ Em nível micro, é possível olhar a parcialidade de cada modo e perceber o todo?

$\checkmark$ Qual modo desempenha um papel mais "importante" em relação a outros?

$\checkmark$ Como cada modo contribui para o significado que está sendo construído?

$\checkmark$ Como os recursos semióticos estão disponíveis para os produtores de signos, e por quem?

Por meio desses questionamentos, podemos perceber a complexidade que reside no processo de composição e interpretação do texto, atribuindo sentido aos diferentes modos semióticos em eventos comunicativos, realizando, assim, uma integração. Para além dessas perguntas, é importante destacar as discussões que a noção de hipertexto traz dentro das concepções de texto que elencamos e o processo de produção e interpretação de sentido. Tal como a epígrafe de Koch (2005, p. 61) que abre esse trabalho "todo texto é um hipertexto", a autora acentua o caráter plurilinear do texto, considerando sua composição e a proposta de sentidos múltiplos.

Algumas características que marcam os textos trazem esse caráter hipertextual, seja impresso ou digital, evidentemente muito demarcado com as propiciações tecnológicas. Para Koch (2005), o hipertexto constitui-se de um suporte linguístico-semiótico hoje intensamente para estabelecer relações virtuais desterritorializadas, marcado por uma escritura nãosequencial e não linear e possibilita ao leitor virtual um acesso ilimitado de outros textos. Noutros termos, Marcuschi (1999) afirma que hipertexto, "trata-se de um processo de leitura e 


\section{PERcursos Linguísticos • Vitória (ES) •v. 11 •n. 29 • 2021 • ISSN: 2236-2592 • Dossiê temático $\bullet O$ texto na pesquisa e no ensino: conhecimentos, práticas e desafios na contemporaneidade •}

escrita multilinearizado, multissequencial e não determinado, realizado em um novo espaço o ciberespaço" (p.1). Para o autor, a novidade propriamente dita está na tecnologia, o que permite integrar de modo eficaz elementos que no texto impresso s estão sob a forma de notas, citações bibliográficas, referências, imagens, diagramas, fotos, "linearizando o deslinearizado e deslinearizando o linerarizado" (p.11).

Em suma, Koch (2005) delineia algumas das principais características para o hipertexto:

Figura 3: Características do hipertexto
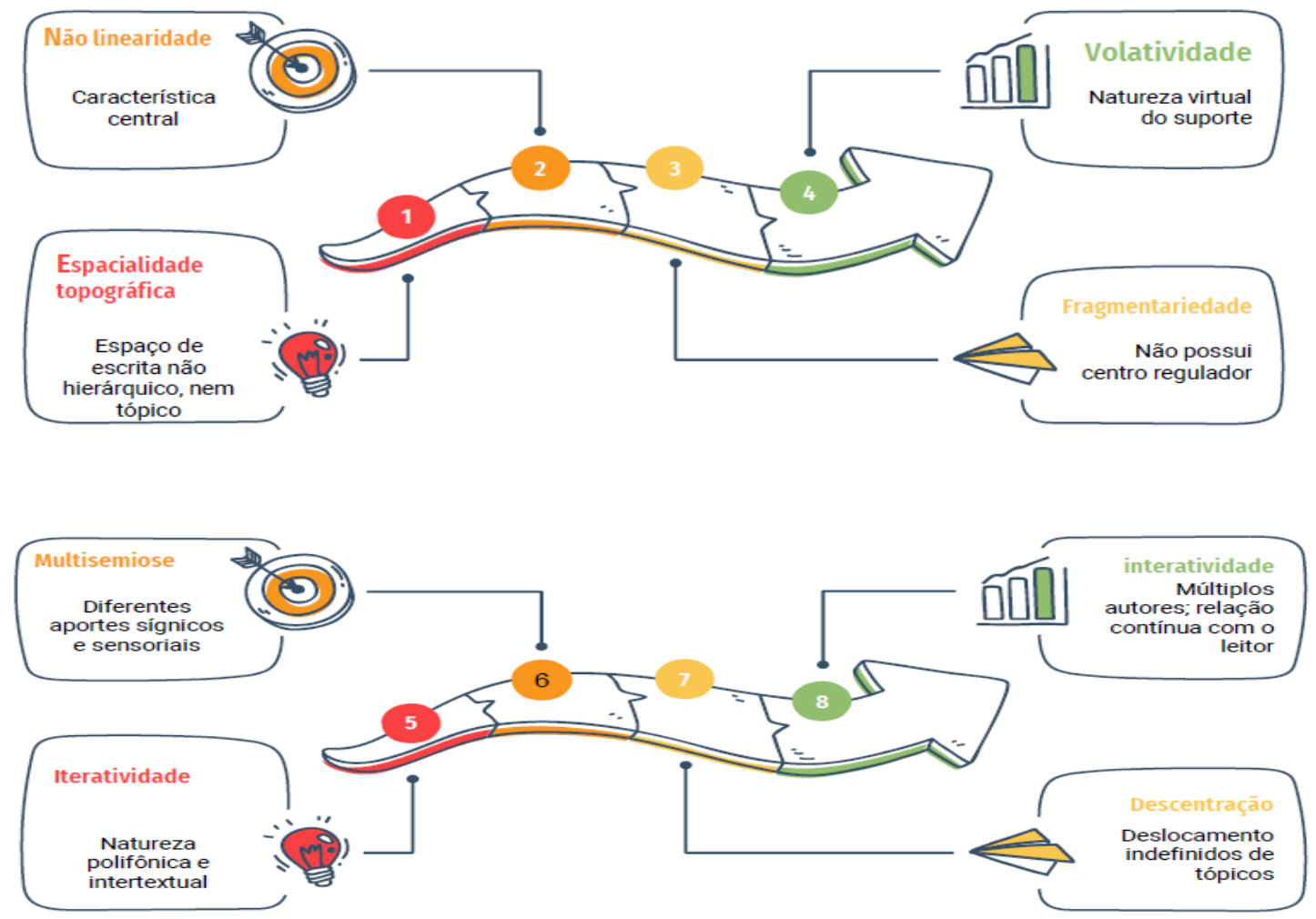

Fonte: baseado em Koch (2005, p. 64)

Dentro desse escopo, Menezes e Nascimento (2009), ao recuperar o histórico do conceito, retomam a visão Ted Nelson (2007), demarcando sua visão sobre design, estruturas e conexões de documentos, situando que as ideias humanas se manifestam como texto, conexões, diagramas e a forma como armazená-los e apresentá-los é um assunto crucial para a civilização. Esse histórico, na visão dos autores, já resolve a polêmica entre os que defendem o caráter hipertextual do pensamento (COSCARELLI, 2002; MARCUSCHI, 2005) e os que não veem uma diferença acentuada entre hipertexto eletrônico e impresso (KOCH, 2005; COSCARELLI, 2002). 


\title{
PERcursos Linguísticos • Vitória (ES) •v. 11 •n. 29 • 2021 • ISSN: 2236-2592 • Dossiê temático $\bullet O$ texto na pesquisa e no ensino: conhecimentos, práticas e desafios na contemporaneidade •
}

A forma de armazenamento e conexão entre as informações no hipertexto se dá por meio de links que são os "elos" ou os "nós" que remetem às informações relacionadas. De acordo com Lévy (1993)

\begin{abstract}
Tecnicamente, um hipertexto é um conjunto de nós ligados por conexões. Os nós podem ser palavras, páginas, imagens, gráficos ou partes de gráficos, sequências sonoras, documentos complexos que podem eles mesmos ser hipertextos. Os itens de informação não são ligados linearmente, como em uma corda com nós, mas cada um deles, ou a maioria, estende suas conexões em estrela, de modo reticular. Navegar em um hipertexto significa, portanto, desenhar um percurso em uma rede que pode ser tão complicada quanto possível. Porque cada nó pode, por sua vez, conter uma rede inteira (p.33).
\end{abstract}

As palavras de Lévy (1993) demarcam a estética de composição dos hipertextos e dimensionam como os caminhos de leitura podem ser trilhados. Esses caminhos serão delineados em decorrência do interesse do leitor, do impacto da multimodalidade como os recursos e modos disponíveis, considerando os princípios e entidades composicionais, os valores de informação (zonas de imagem) como saliência, molduras etc. Desse modo, vemos como a multimodalidade impacta no design dos hiper(textos), o que requer do leitor cuidado e análise para delinear os caminhos de leitura, para que a orquestração dos modos semióticos seja coerente e compatível com a perspectiva do todo do hipertexto, o que pode resultar, segundo Xavier (2002), um deslocamento ou desvio no sentido da incongruência e da insustentabilidade dos posicionamentos assumidos em um texto eletrônico.

Agasalhando as palavras de Marcuschi (1999), a leitura do hipertexto é como uma viagem por trilhas. Ela nos obriga a ligar esses nós para formar redes de sentido. A ligação desses nós consiste em olhar para as partes e construir o sentido do todo, ou seja, atentar-se para parcialidade de cada modo, o papel que cada um desempenha em relação a outros modos e como os recursos semióticos vão sendo articulados no trabalho semiótico de produção sentido (meaning making) do texto. Desse modo, um dos desafios para os estudos da linguagem é ver como os leitores operam com textos múltiplos bem como dimensionar os desdobramentos da visão plurilinear do texto na sua construção e, consequentemente, na leitura. Logo, é elementar uma lente multimodal para a leitura e análise dos textos.

\section{Análise Multimodal: alguns percursos metodológicos}

Considerando a importância de uma lente multimodal para olhar para os (hiper)textos, questionamo-nos: O que seria uma análise multimodal? Como fazer análise Multimodal? Para 


\section{PERcursos Linguísticos • Vitória (ES) •v. 11 •n. 29 • 2021 • ISSN: 2236-2592 • Dossiê temático $\bullet O$ texto na pesquisa e no ensino: conhecimentos, práticas e desafios na contemporaneidade •}

que fazer uma análise multimodal? Menos preocupados em ter respostas objetivas e mais engajados em compreender o trabalho semiótico, as escolhas realizadas dentro do (hiper)texto e os desdobramentos para a produção de sentidos na leitura e na escrita é elementar olhar para o (hiper)texto e compreender o papel de cada modo e como pode contribuir para construção de significados e a materialidade discursiva. Ressaltamos que esse trabalho transcende uma visão descritiva que se apoia em observar a articulação dos modos e o que eles podem dizer em termos de significados funcionais (representacionais, interacionais ou composicionais), conforme explicitam Kress e van Leeuwen (2006) na Gramática do Design Visual. Uma análise multimodal de texto implica:

$\checkmark$ Reconhecer a diferença entre os modos semióticos, a sua disponibilidade em cada comunidade comunicativa e a motivação de suas escolhas dentro do contexto cultural;

$\checkmark$ Reconhecer as diferenças e especificidades em cada situação contextual em que os modos e recursos são combinados para produzir sentidos;

$\checkmark$ Atentar para todos os modos, com o mesmo nível de detalhe.

Buscando ancorar a teoria em exemplos de práticas sociais de linguagem que se deflagram cotidianamente, Kress (2010) situa que [...] "o banal, o cotidiano e o normal é sempre o melhor local [...]" (p. 67 $7^{8}$ ). Logo, o nosso olhar precisa partir daquilo que nos rodeia, que desperta nossa curiosidade, das nossas práticas cotidianas. Por meio dessa perspectiva, desse banal, que nossas indagações ganham espaço e permitem-nos pensar sobre os dados, como coletá-los, como analisá-los etc. É importante compreender as preferências modais de determinadas culturas e os propósitos comunicacionais ensejados em cada situação comunicativa. Além desse horizonte, podemos investigar qual referencial teórico/teorias pode nos oferecer sustentação para compreender esses dados. A abordagem multimodal oferece um inventário analítico para investigar os meios materiais de representação, os modos, contudo, ela em si não dá envergadura para o mapeamento dos sentidos que são mediados por meio de sistemas e recursos semióticos, tendo em conta as dinâmicas culturais e ideológicas nas quais eles estão imersos. Por isso, já que a multimodalidade não é uma teoria, toda análise multimodal precisa elucidar a teoria que fundamenta esta forma de olhar para os modos semióticos de um

\footnotetext{
${ }^{8}$ Tradução de: "The banal, the everyday and unremarkable is always the best site to anchor theory". (KRESS, 2010, p. 67).
} 


\section{PERcursos Linguísticos • Vitória (ES) •v. 11 •n. 29 • 2021 • ISSN: 2236-2592 • Dossiê temático $\bullet O$ texto na pesquisa e no ensino: conhecimentos, práticas e desafios na contemporaneidade •}

texto. No contexto deste artigo, trabalhamos com a multimodalidade a partir da Semiótica Social. Esse percurso metodológico é esboçado na Fig. 4.

Figura 4: Percursos Metodológicos

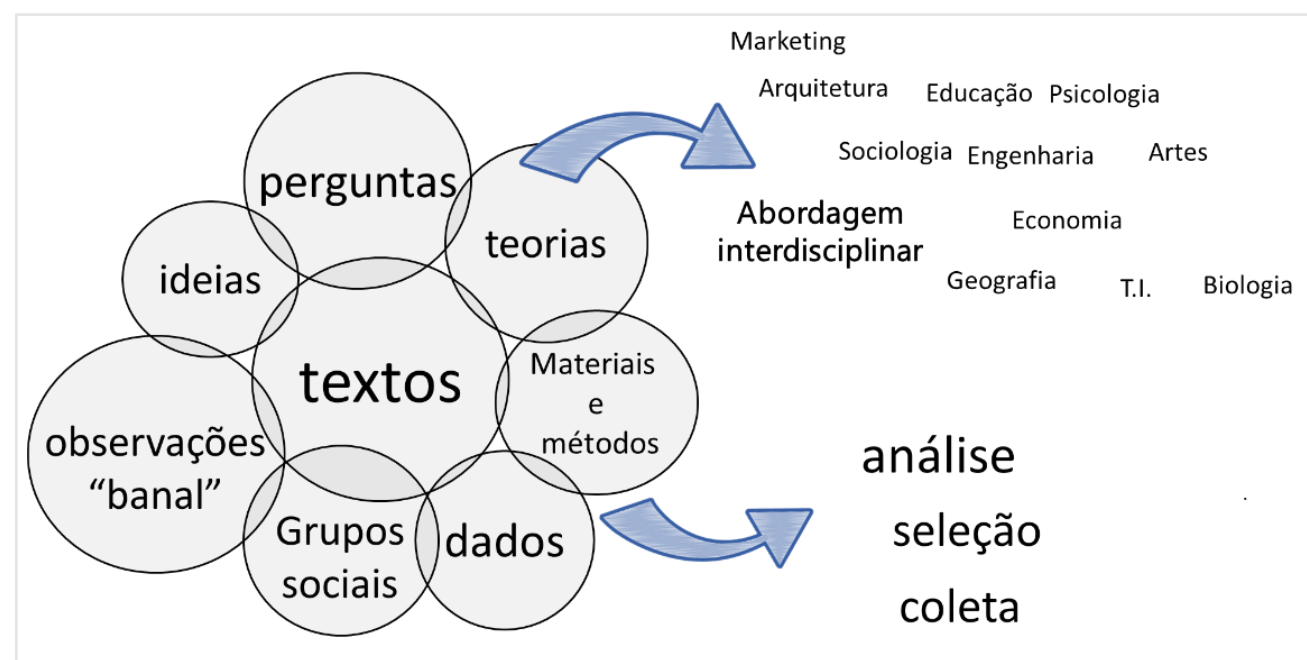

Fonte: elaboração das autoras

A Fig. 4 traz o texto como ponto em comum em todo o processo de análise. A partir dos textos com os quais interagimos em nosso cotidiano, refletimos e construímos ideias, que nos movem a elaborar perguntas. Para responder a esses questionamentos, precisamos buscar teorias relacionas às áreas envolvidas. Por exemplo, se o texto analisado é um filme, é necessário pesquisar autores das áreas de cinema, música, entre outras. Se é um jogo eletrônico, outros campos de conhecimento estão envolvidos. Cabe ao pesquisador selecionar essas teorias e estabelecer relações com seu objeto de estudo e com as questões sociais envolvidas (poder, identidade etc).

Assim, numa análise multimodal sob a ótica da Semiótica Social, nossas indagações partem da teia social em que estamos imersos. Investigamos, com uma visão holística, fenômenos por meio da seleção, coleta e análise de dados que possam contribuir com o entendimento do tecido social. Nas palavras de Kress (2010), “o social é motor da mudança comunicacional/semiótica, para a constante reprodução de recursos culturais/semióticos; e para 


\section{PERcursos Linguísticos • Vitória (ES) •v. 11 •n. 29 • 2021 • ISSN: 2236-2592 • Dossiê temático $\bullet O$ texto na pesquisa e no ensino: conhecimentos, práticas e desafios na contemporaneidade •}

a produção do novo" (p. $35^{9}$ ). Nesses moldes, a análise é mais que uma descrição de modos que compõem um determinado (hiper)texto. É preciso pensar em como se articulam, como se dá a sua composição; uma análise multimodal precisa contribuir com a dinâmica dos sentidos e com as dinâmicas culturais, em compreender as necessidades/objetivos de comunicação bem como suas mudanças. Logo, é necessário refletir sobre as escolhas motivadas, os signos criados, o design dos textos, os modos e recursos que vão tecendo esses textos, quais necessidades comunicativas precisam ser alcançadas dentro de um contexto cultural etc. A partir dessas compreensões e investigações, podemos sair de uma postura descritiva da multimodalidade e chegar a uma análise mais profunda das camadas dos textos.

\section{(In)conclusões}

As considerações tecidas até aqui buscam fomentar algumas reflexões sobre multimodalidade e (hiper)textos, pensando a leitura e escrita em tempos de mudanças constantes na paisagem semiótica, para desenvolver caminhos em nossas pesquisas. Sem a pretensão de ter respostas exatas ou objetivas, nosso intuito residiu em ressaltar os desafios para a linguística de como os leitores operam com textos múltiplos bem como os desdobramentos de uma visão plurilinear do texto e sua construção.

Elencamos um conjunto de conceitos da teoria da Semiótica Social Multimodal e como eles nos direcionam para olhar para a produção de signo (sign-making) e sentidos (making meaning), compreendendo a dinâmica da distribuição de poder e agências de controle - cruciais para a compreensão dos ambientes de comunicação. Mais do que reafirmar a multimodalidade presente nos hipertextos, nos questionamos sobre os movimentos de leituras e as trilhas que seguimos para criar conexões, ligar os "nós" e formar redes de sentido. Observamos que, num cenário em que o (hiper)texto pode ser produzido em ambientes digitais marcados pela não linearidade, fragmentalidade, interatividade, dentre outros aspectos, vale questionar, segundo Kress (2010), a noção de autoria, que vai além de uma visão anacrônica de plágio, carecendo de teorização. Na perspectiva do autor, é necessário observar os movimentos colaborativos de escrita bem como observar os rearranjos no poder que podem ser conceituados como uma mudança de estruturas de poder vertical para horizontal, de relações hierárquicas (pelo menos aparentemente) mais abertas, relações mais participativas, capturadas em muitos aspectos da comunicação contemporânea.

\footnotetext{
9 Tradução de: "the social is the motor for communicational/ semiotic change; for the constant remaking of cultural/semiotic resources; and for the production of the new" (KRESS, 2010, p. 35).
} 


\section{PERcursos Linguísticos • Vitória (ES) •v. 11 •n. 29 • 2021 • ISSN: 2236-2592 • Dossiê temático $\bullet O$ texto na pesquisa e no ensino: conhecimentos, práticas e desafios na contemporaneidade •}

Distante de chegar a uma conclusão, temos um caminho longo a percorrer para ir compreendendo a dinâmica das mudanças na comunicação e os desdobramentos para a produção escrita e de leitura dos (hiper)textos. Logo, se atentarmos para as mudanças sociais, e para os textos como efeitos dessas mudanças, temos um ponto de partida para as investigações e compreensão da relação dialética entre comunicação e sociedade.

\section{Referências}

BAKHTIN. M. O problema do texto na linguística, na filosofia e em outras ciências humanas. In: Estética da criação verbal. Trad. Paulo Bezerra.4 ed. São Paulo: Martins Fontes, 2006b, pp.307-335[1959-1961].

BARBOSA. V. S. Multimodalidade e Letramento Visual: uma proposta de intervenção pedagógica para integrar as habilidades de ler e ver no processo de ensino e aprendizagem de inglês como língua estrangeira. Tese (doutorado) - Universidade Estadual do Ceará, Centro de Humanidades, Programa de Pós-Graduação em Linguística Aplicada, Fortaleza, 2017.

BEZEMER, J.; KRESS, G. Multimodality, Learning and Communication. London: Routledge, 2016.

COLLOW, J. Literacy and the visual: broadning our vision. English Teaching: Practice and Critique, vol. 4, n.1, May, 2005, pp 6-19.

COSCARELLI, C. V. Entre textos e hipertextos. In: COSCARELLI, C. V. (Org.). Novas tecnologias, novos textos, novas formas de pensar. Belo Horizonte: Autêntica, 2002.

GOODWIN, C. Action and embodiment within situated human interaction. Journal of Pragmatics 32 (2000) p. 1489-1522. Disponível em: 〈http: www.elsiever.nl/locate/pragma〉

GUALBERTO. C. Multimodalidade em livros didáticos de língua portuguesa: uma análise a partir da semiótica social e da gramática do design visual. Tese (doutorado) - Universidade Federal de Minas Gerais, Faculdade de Letras, 2016.

GUALBERTO. C.; SANTOS, Z. Multimodalidade no contexto brasileiro: um estado de arte. Revista D.E.L.T.A., 35-2, 2019 (1-30).

GUALBERTO, C.; SANTOS, Z.; MEIRA, A. C. Multimodal metaphors: from language as a condition to text to the notion of texture as a meaning-making semiotic resource. Revista de Estudos da Linguagem, n. 28, v. 2, 2020.

HALLIDAY, M. A. K.; HASAN, R. Cohesion in English. London: Longman, 1976.

HALLIDAY, M. A. K. Language as social semiotic. London: Edward Arnold, 1978. 


\section{PERcursos Linguísticos • Vitória (ES) •v. 11 •n. 29 • 2021 • ISSN: 2236-2592 • Dossiê temático $\bullet O$ texto na pesquisa e no ensino: conhecimentos, práticas e desafios na contemporaneidade •}

HEBERLE, V. M.; ABREU, B. B. Investigating Multimodality: An analysis of students' diary journals. Revista do Programa de Pós-Graduação em Linguística Aplicada da UECE Linguagem em Foco - volume 3. N. 5, ano 2011.

HODGE, R.; KRESS, G. Social Semiotics. New York: Cornell University Press, 1988.

KOCH, I. G. V. A construção de sentidos no hipertexto: demandas linguísticas e cognitivas. In: ENCONTRO NACIONAL SOBRE HIPERTEXTO, 1, 2005, Recife. Anais. Disponível em: <www.ufpe.br/hipertexto2005/TRABALHOS/ Ingedore.htm>. Acesso em: 26 set. 2007.

KOCH, I. G. V. Desvendando os segredos do texto. 4 ed. São Paulo: Cortez, 2005.

KOCH, I. G. V.; ELIAS, V. M. Ler e escrever: estratégias de produção textual. São Paulo: Contexto, 2009.

KRESS, G. Before Writing. London: Routledge, 1997.

KRESS, G. Multimodality: A Social Semiotic Approach to Contemporary Communication. London: Routledge, 2010.

KRESS, G. Discourse Analysis and Education: A Multimodal Social Semiotic Approach. In: ROGER, Rebecca (Org). An Introduction to Critical Discourse Analysis in Education. London:

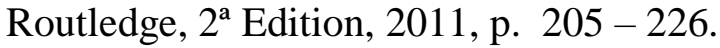

KRESS, G. Semiotic work: Applied Linguistics and a social semiotic account of Multimodality. AILA Review 28 (2015), 49-71.

KRESS, G.; BEZEMER, J. Writing in a multimodal world of Representation. In BEARD, R.; MYHILL, D.; NYSTRAND, M.; RILEY, J. (Eds.). SAGE Handbook of Writing Development (pp. 167-181). London: Sage, 2009.

KRESS, G.; VAN LEEUWEN, T. Multimodal Discourse: The modes and media of contemporary communication. London: Arnold, 2001.

KRESS, G.; VAN LEEUWEN, Theo. Front Pages: (The critical) analysis of newspaper layout. In BELL, Allan; GARRET, Peter. (Eds.) Approaches to media discourse. Blackwell Publishing, 1998. p. 186-219.

LÉVY, Pierre. As tecnologias da inteligência: o futuro do pensamento na era da informática. Rio de Janeiro: Editora 34, 1993.

MARCUSCHI, L. A. Heráclito e o hipertexto: o logos do hipertexto e a harmonia do oculto. In: ENCONTRO NACIONAL SOBRE HIPERTEXTO, 1, 2005, Recife. Anais. Disponível em: <www.ufpe.br/hipertexto2005/TRABALHOS/Marcuschi\%20(Confer\%EAncia.htm>. Acesso em: 27 out. 2008.

MARCUSCHI, L. A. Linearização, cognição e referência: o desafio do intertexto. Comunicação apresentada no IV Colóquio da Associação Latinoamericana de Analistas do Discurso. Santiago, Chile, Abril, 1999. 


\section{PERcursos Linguísticos • Vitória (ES) •v. 11 •n. 29 • 2021 • ISSN: 2236-2592 • Dossiê \\ temático $\bullet O$ texto na pesquisa e no ensino: conhecimentos, práticas e desafios na contemporaneidade •}

MENEZES, V.; NASCIMENTO, M. (Org.) Sistemas adaptativos complexos: lingua(gem) e aprendizagem. Belo Horizonte: Faculdade de Letras/FAPEMIG, 2009.

NELSON, T. H. Transliterature. 2007. Disponível em: <http://transliterature.org/>. Acesso em: 2 set. 2019.

PAIVA, V. L .M. O; NASCIMENTO, M. Texto, hipertexto e a (re)configuração de (com)textos. In: LARA, G. M. P. (Org.). Lingua(gem), texto, discurso: entre a reflexão e a prática. v. 1. Rio de Janeiro: Lucerna; Belo Horizonte: FALE/UFMG, 2006. p. 155-179.

PAIVA, V. L. M. O; NASCIMENTO, M. Hipertexto e Complexidade. Linguagem em (Dis)curso, Palhoça, SC, v.9, n.3, p. 519-547, set/dez. 2009.

PIMENTA, S. M. O. P. O signo da receptividade: uma visão sócio-construcionista da interação. Belo Horizonte: Faculdade de Letras da UFMG, 2006.

SANTOS, Z. B. A representação e a interação verbal e visual: uma análise de capas e reportagens de revistas na perspectiva da Gramática Sistêmico-Funcional e da Gramática do Design Visual. Tese (doutorado) - Universidade Federal de Minas Gerais, Faculdade de Letras, 2013.

VAN LEEUWEN, T. Multimodal Literacy. Viden Om Literacy, n. 21, 2017.

XAVIER, A. C. O hipertexto na sociedade de informação: a constituição do modo de enunciação digital. Tese (Doutorado em Linguística) - IEL, UNICAMP, 2002. 